\title{
An oceanic pathway for Madden-Julian Oscillation influence on Maritime Continent Tropical Cyclones
}

\author{
Karthik Balaguru ${ }^{1 凶}$, L. Ruby Leung $\mathbb{D}^{1}$, Samson M. Hagos ${ }^{1}$ and Sujith Krishnakumar (iD
}

While the Madden-Julian Oscillation (MJO) has been shown to affect tropical cyclones (TCS) worldwide through its modulation of large-scale circulation in the atmosphere, little or no role for the ocean has been identified to date in this influence of MJO on TCs. Using observations and numerical model simulations, we demonstrate that MJO events substantially impact TCs over the Maritime Continent $(\mathrm{MC})$ region through an oceanic pathway. While propagating across the $\mathrm{MC}$ region, MJO events cause significant sea surface cooling with an area-averaged value of about $0.35 \pm 0.12^{\circ} \mathrm{C}$. Hence, $\mathrm{TCs}$ over the $\mathrm{MC}$ region immediately following the passage of MJO events encounter considerably cooler sea surface temperatures. Consequently, the enthalpy fluxes under the storms are reduced and the intensification rates decrease by more than $50 \%$ on average. These results highlight an important role played by the ocean in facilitating MJO-induced sub-seasonal variability in TC activity over the MC region.

npj Climate and Atmospheric Science (2021) 4:52; https://doi.org/10.1038/s41612-021-00208-4

\section{INTRODUCTION}

The Madden-Julian Oscillation (MJO), a 30-60 days period oscillation is a dominant mode of variability in the tropical atmosphere. It is one of the most important meteorological phenomena at intraseasonal timescales with wide-ranging impacts on global weather and climate ${ }^{1-3}$. While the wet or active phase of the MJO is associated with enhanced convection, the dry or suppressed phase is less conducive for convection ${ }^{3,4}$. Thus, when the active phase of the MJO happens over a region, the large-scale environment becomes more favorable for cyclogenesis, leading to the formation and intensification of tropical cyclones (TCs) in that region ${ }^{5,6}$. It has been observed that TCs tend to form in clusters in different basins coinciding with the favorable or active phase of the $\mathrm{MJO}^{7}$. Reduction in vertical wind shear, enhancement of low-level cyclonic vorticity and an increase in mid-tropospheric humidity are found to be the main factors behind the MJO's positive influence on TCs in various regions ${ }^{8-19}$.

While the MJO's modulation of the atmosphere is well known, its impact on the upper-ocean has been less clear, and consequently, the latter became one of the main focal points of the Dynamics of the Madden-Julian Oscillation (DYNAMO) field campaign ${ }^{20}$. Besides changes in cloud cover and precipitation, the MJO is also associated with strong surface wind variations. Their joint impact on surface buoyancy and momentum fluxes triggers a significant response from the ocean mixed layer, and consequently the sea surface temperature (SST) ${ }^{21-29}$. Several studies have shown that a prominent feature of the oceanic response to MJO forcing during the active phase is a SST cooling and a reduction in upper-ocean heat content over a broad area in the eastern equatorial and southeast Indian Ocean regions, which has particular relevance to TCs. Since TCs intensify by extracting heat energy from the ocean, SSTs play a critical role in their development ${ }^{30-33}$. Despite this, the impact of MJO-induced SST cooling on TCs has not been explored to date. In this study, using a suite of observations and numerical model simulations, we demonstrate that TCs over the Maritime Continent (MC) region are influenced significantly by MJO-induced SST cooling.

\section{RESULTS}

\section{Upper-ocean response to MJO}

The composite mean upper-ocean response to the active convective phase of the MJO is characterized by a broad region of SST cooling over the $\mathrm{MC}$ region, extending approximately between $105^{\circ} \mathrm{E}-150^{\circ} \mathrm{E}$ and $20^{\circ} \mathrm{S}$-Equator (Fig. 1a). This pattern of SST cooling over the $M C$ region stands out as a unique response of the ocean to the MJO in the entire tropics (Supplementary Fig. 1). The maximum SST cooling occurs to the northwest of Australia and exceeds $1{ }^{\circ} \mathrm{C}$. This composite is based on nearly $90 \mathrm{MJO}$ events between 1982 and 2019. MJO-induced SST cooling here is defined as the difference in SST between the end of phase 5 and the beginning of phase 3 , which roughly represents the period during the MJO's lifecycle when it crosses the MC region ${ }^{34,35}$. The MJO phase and its amplitude correspond to its location and strength, respectively, as defined by the daily real-time multivariate MJO (RMM) index ${ }^{36}$. The tendency of the MJO to induce significant cooling over the $M C$ region was also noted in previous studies $^{22,23}$. This composite is based on the National Oceanic and Atmospheric Administration's Optimum Interpolation SST (NOAA OI SST), which only assimilates infrared satellite data, and hence could be influenced by cloud-effects. To address this, we also computed the composite using Tropical Rainfall Measuring Mission (TRMM) SST that is based on microwave satellite data (Fig. 1b). The signal, based on 41 MJO events over the period 1998-2014, is broadly consistent with that obtained earlier in terms of the spatial pattern but is stronger in magnitude, especially in certain areas to the south of Java and over the Banda Sea, suggesting that the infrared satellite-based data likely underestimates the SST response to MJO.

The temporal evolution of MJO-induced SST cooling based on NOAA OI SST, averaged over the region $110^{\circ} \mathrm{E}-130^{\circ} \mathrm{E}$ and $15^{\circ} \mathrm{S}-5^{\circ} \mathrm{S}$, demonstrates the persistence of the oceanic response to MJO forcing (Fig. 1c). Beginning on day 0 , which represents the first day of MJO phase 3, SST cools rapidly until around day 20 with the magnitude of area-averaged cooling reaching a maximum value of about $0.35 \pm 0.12^{\circ} \mathrm{C}$. The time taken by the MJO event to progress from the beginning of phase 3 to the end of phase 5 is

\footnotetext{
'Pacific Northwest National Laboratory, Richland, WA, USA. ${ }^{\circledR}$ email: Karthik.Balaguru@pnnl.gov
} 

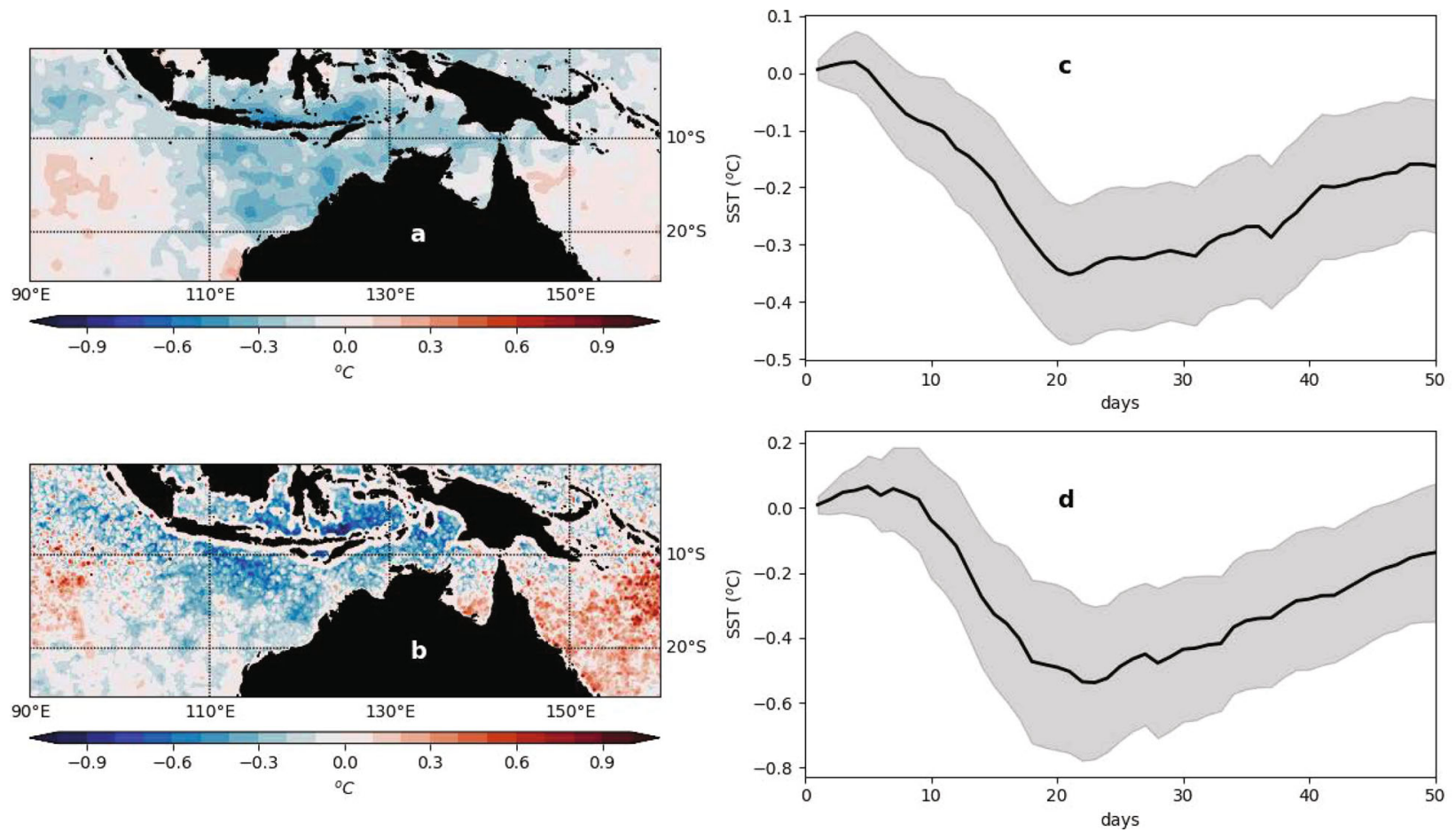

Fig. 1 SST response to MJO-forcing over the MC. a Composite mean upper-ocean response to the MJO based on NOAA OI SST ( $\left.{ }^{\circ} \mathrm{C}\right)$ for the period 1982-2019. The composite is generated from $91 \mathrm{MJO}$ events over the 38-year period. b Composite mean upper-ocean response to the MJO based on TRMM SST ( $\left.{ }^{\circ} \mathrm{C}\right)$ for the period 1998-2014. The composite is generated from 41 MJO events over the 17-year period. c Composite mean time evolution of SST $\left({ }^{\circ} \mathrm{C}\right)$, based on NOAA OI SST and MJO events identified in (a). d Composite mean time evolution of SST ( $\left.{ }^{\circ} \mathrm{C}\right)$, based on TRMM SST and MJO events identified in (b). In panels (c, d), the SST is averaged over the region $110^{\circ} \mathrm{E}-130^{\circ} \mathrm{E}$ and $15^{\circ} \mathrm{S}-5^{\circ} \mathrm{S}$, and the gray shading represents the $95 \%$ confidence intervals computed as 1.96 times the standard error.

$15 \pm 7$ days, which is in good agreement with the timing of the peak SST cooling. Beyond day 20, the recovery of SST is a rather slow process. On day 50, nearly a month after the maximum cooling occurs, the average cooling is still nearly $0.2^{\circ} \mathrm{C}$ below the pre-active phase MJO SST. The time evolution of MJO-induced SST cooling based on TRMM microwave SST (Fig. 1d) is in good agreement with that obtained using NOAA OI SST. Considering the composite mean, the maximum SST cooling occurs on day 22 albeit with a stronger magnitude of about $0.54 \pm 0.23^{\circ} \mathrm{C}$. Beyond this, the SST anomaly recovers slowly and the cooling reaches a value of about $0.30 \pm 0.21{ }^{\circ} \mathrm{C}$ on day 50 .

To identify the role of various upper-ocean processes in the MJO-induced SST cooling over the MC region, a mixed layer heat budget analysis was performed using an eddy-permitting ocean reanalysis that assimilates satellite SSTs and all available hydrographic measurements, including data from Argo floats ${ }^{37}$. The analysis, broadly consistent with previous studies ${ }^{38-40}$, reveals that both surface fluxes at the air-sea interface and vertical processes in the sub-surface ocean are responsible for the SST change under the MJO, and that the shallow seas and climatological mean mixed layers in the MC region play an important role in its larger SST response compared to other regions (see Supplementary Note 1).

\section{Impact on TCs}

The region to the north of Australia over the $\mathrm{MC}$ region is home to nearly $15 \%$ of global TC activity ${ }^{41}$. Further, the region to the northwest of Australia, between $110^{\circ} \mathrm{E}-130^{\circ} \mathrm{E}$ and $20^{\circ} \mathrm{S}-10^{\circ} \mathrm{S}$, happens to be the most TC-prone region in the entire Southern Hemisphere with $75 \%$ of the most intense Australian TC landfalls occurring along the coast here ${ }^{42}$. Although this region is sparsely populated, it has much commercial significance ${ }^{10}$, particularly oil and gas ${ }^{43}$ production. Earlier, we have seen how MJOs induce substantial sea surface cooling over this region while crossing the
$\mathrm{MC}$ region. Further, the TC season over this region extends from December to April ${ }^{42}$, coinciding with the seasonal peak of MJO activity over the $M C$ region ${ }^{44}$. Thus, the natural question it leads us to is whether the MJO-induced SST cooling can influence TCs to the northwest of Australia. To answer this, we performed a Lagrangian along-track composite analysis of the large-scale ocean-atmosphere environment affecting TCs for the 34-year period 1985-2018 (see "Methods").

Between days 5 and 24 after the beginning of the MJO event, the atmosphere is highly favorable for TCs (Supplementary Table 1). This roughly corresponds to phases 3-5 of the MJO and represents the time during which the active phase of the MJO passes through the $M C$ region. Though the sea surface begins to cool, the atmosphere is very conducive for TC development over this period. On average, the vertical shear of zonal wind is more easterly, the $700 \mathrm{hPa}$ relative humidity increases by $4.5 \%$, the lowlevel relative vorticity is more cyclonic, the outgoing longwave radiation is reduced by $15.65 \mathrm{~W} \mathrm{~m}^{-2}$ and the sea-level pressure drops by nearly $200 \mathrm{~Pa}$ (Supplementary Table 1). Consequently, the mean TC intensification rate increases by about $0.6 \mathrm{~m} \mathrm{~s}^{-1}$ 6-hr $\mathrm{h}^{-1}$, and more than $40 \%$ of all western Australian 6-hourly TC track locations are found during this period. These results are in line with those from previous studies that have suggested the MJO's favorable influence on TCs in this region during phases $3-5^{6,10}$. Note that data here have been sub-sampled so that distributions of TC initial intensity and translation speed are statistically similar between sample sets used for comparison to ensure that the results are not contaminated by variations in storm characteristics (see Supplementary Table 1).

Subsequently, between days 24 and 41, which roughly represents the period after the MJO-active phase has left the $M C$ region, the positive atmospheric influence of the MJO subsides to a large extent and significant sea surface cooling prevails over this region (Fig. 1c, d). The number of 6-hourly TC 

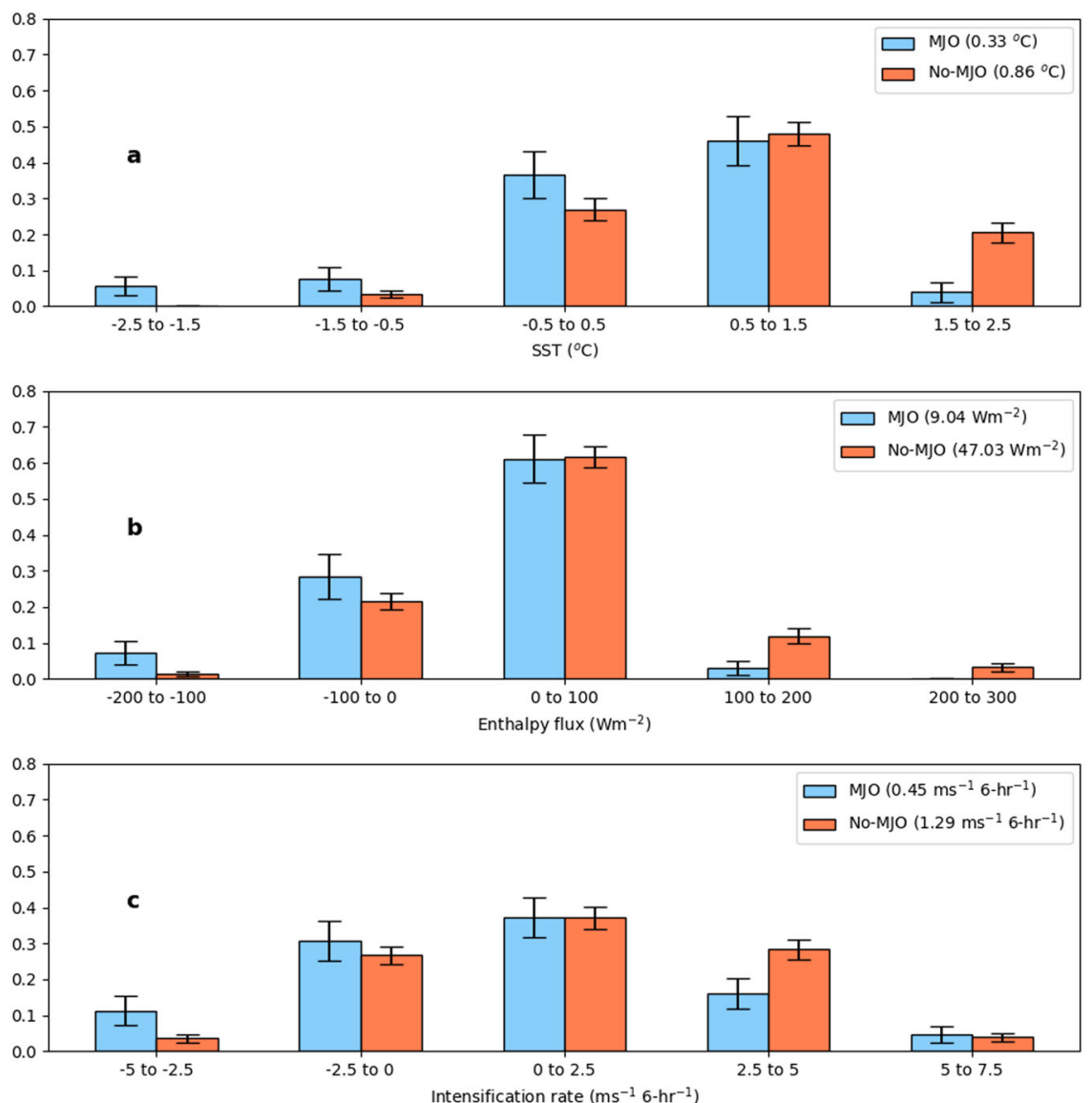

Fig. 2 Observed impact of MJO on TCs. a Probability distribution functions (PDFs) of pre-storm SSTs $\left({ }^{\circ} \mathrm{C}\right)$. $\mathbf{b}$ Enthalpy fluxes under TCs at the air-sea interface $\left(\mathrm{W} \mathrm{m}^{-2}\right)$. c TC intensification rates $\left(\mathrm{m} \mathrm{s}^{-1} 6-\mathrm{hr}^{-1}\right.$. The PDFs in blue (denoted as "MJO") correspond to those TC track locations that fall within the MJO's Window of Oceanic Influence (MWOI), and the PDFs in orange (denoted as "No-MJO") correspond to those that fall outside the MWOI. In each panel, the mean values are shown in the legend and the error bars representing the standard deviation (s.d.), generated based on the Monte Carlo technique (see "Methods"), are indicated. The difference between mean values are statistically significant at the $95 \%$ level for each parameter. The analysis is based on NOAA OI SST, Woods Hole Oceanographic Institution's Objectively Analyzed air-sea Fluxes for the Global Oceans (WHOI OAFlux), and TC best track data.

track locations during this period decreases to $20 \%$, likely due to the reduced MJO's positive influence on cyclogenesis through the atmospheric pathway. We denote this period as the MJO's Window of Oceanic Influence (MWOI). To clearly isolate the role of MJO-induced oceanic cooling on TC intensification during this period, we sub-sample the data so that in addition to distributions of initial storm characteristics, distributions of pre-storm atmospheric parameters are also statistically similar between sample sets used for comparison (see Supplementary Table 2). This is necessary because a period of suppressed MJO convection typically follows the convectively active phase ${ }^{22}$, thus raising a possibility for some potential atmospheric influence to act on top of that from the ocean. The pre-storm SST anomaly for TCs outside the MWOI is $0.86{ }^{\circ} \mathrm{C}$, which reduces significantly to $0.33^{\circ} \mathrm{C}$ inside the MWOI representing a decrease of $0.53^{\circ} \mathrm{C}$. In response to this cooling, the anomalous dry stability in the lower troposphere $(1000-850 \mathrm{hPa})$ increases by $0.0024 \mathrm{~K} \mathrm{~Pa}^{-1}$ and the anomalous enthalpy flux out of the ocean reduces from about $47 \mathrm{~W} \mathrm{~m}^{-2}$ outside the MWOI to about $9 \mathrm{~W} \mathrm{~m}^{-2}$ inside the MWOI, indicating a reduction of about $38 \mathrm{~W} \mathrm{~m}^{-2}$. Consequently, the TC intensification rates are significantly reduced inside the window. While the mean intensification rate outside the MWOI is $1.29 \mathrm{~m} \mathrm{~s}^{-1} 6-\mathrm{hr}^{-1}$, it reduces by more than $50 \%$ to $0.45 \mathrm{~m} \mathrm{~s}^{-1} 6-\mathrm{hr}^{-1}$ within the MWOI.

The probability distribution functions (PDFs) of pre-storm SSTs, enthalpy fluxes under TCs and the $24 \mathrm{hr}$ TC intensification rates further reinforce these results (Fig. 2). Compared to the PDFs for TC locations outside the MWOI, the PDFs for TC track locations inside the MWOI are skewed to the left indicating relatively lower pre-storm SSTs (Fig. 2a) and air-sea enthalpy fluxes (Fig. 2b), and a reduction in $\mathrm{TC}$ intensification rates (Fig. $2 \mathrm{c}$ ) for the latter. These differences are statistically significant at the $95 \%$ level based on the Student's $t$-test for difference of the means. Although we attribute differences in enthalpy fluxes under TCs to those in prestorm SST differences, minor contributions are also possible from differences in surface winds (see Supplementary Note 2). Some previous studies suggested that the potential intensity for a TC, and consequently its intensification, is more closely related to the relative SST or the absolute SST minus the tropical mean $\mathrm{SST}^{45}$. A sensitivity test indicates that similar results are obtained when absolute SST is replaced with relative SST in our analysis. Although these results strongly support the role of MJO-induced oceanic cooling in suppressing TC intensification inside the MWOI, we acknowledge that the ocean's negative impact on TCs may be modulated by some lingering atmospheric effects of the MJO.

\section{Model}

While results presented thus far are based on observations, numerical simulations of Cyclone Olga using a high-resolution regional atmospheric model (see "Methods") provide further support. Olga, a tropical storm from the 1999-2000 Australian 

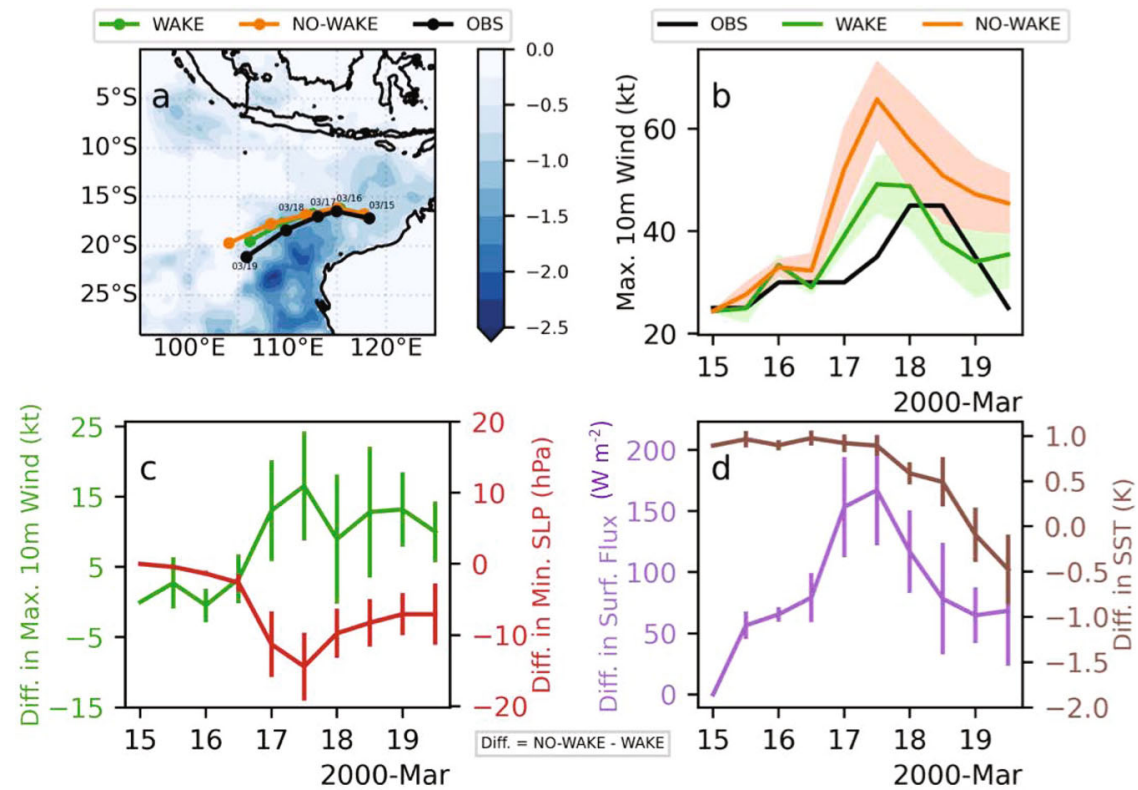

Fig. 3 Simulating MJO's impact on TC Olga (2000). a Track of TC Olga from observations (black) and model simulations (WAKE (green) and NO-WAKE (orange)). While the "WAKE" case represents the set of simulations where the model is forced by observed SST, the "NO-WAKE" case represents the set of simulations where the model is forced by SSTs from which the influence of MJO is removed. Both "WAKE" and "NOWAKE" each consist of 8 simulations and the ensemble mean tracks are shown. The color in the background represents the SST change induced by prior MJO, just before Olga's formation on 15 March 2000. Dates are shown near tracks to indicate the direction of Olga's movement. b Time evolution of Olga's $10 \mathrm{~m}$ maximum winds (kt) from observations and model simulations. Time evolution of difference between NO-WAKE and WAKE simulations for (c) $10 \mathrm{~m}$ maximum wind (kt, green) and minimum sea-level pressure (hPa, red), and (d) alongtrack pre-storm SST $\left({ }^{\circ} \mathrm{C}\right.$, brown) and enthalpy flux at the air-sea interface under the storm $\left(\mathrm{W} \mathrm{m}^{-2}\right.$, purple). As in panel (a), ensemble mean values are shown in panels $(\mathbf{b}-\mathbf{d})$. The shading in panel $(\mathbf{b})$, and the vertical bars in panels $(\mathbf{c}$, $\mathbf{d})$, indicate the ensemble spread as represented by the s.d.

cyclone season formed in the Timor Sea on 15 March 2000 in the aftermath of a MJO event that began on 1 March and appears to have traversed the SST cooling induced by the MJO (Fig. 3a). To understand the impact of the upper-ocean response to MJO on Olga, we performed two sets of simulations with and without the MJO-induced SST cooling (see "Methods"). The tracks from the simulations are in good agreement with the observed track of Olga and the storm follows a similar trajectory after formation (Fig. 3a). In the control simulation (WAKE), the time evolution of Olga's intensity agrees reasonably with the observed despite some differences (Fig. 3b). For instance, the peak intensity for Olga is higher by about $3 \mathrm{kt}$ and is attained nearly a day earlier. Despite these, the model captures the salient features of Olga's life-cycle and provides a good baseline for comparison.

When the MJO-induced SST cooling is removed from the forcing (NO-WAKE), the intensity of Olga increases considerably (Fig. 3b). While previously Olga remained a tropical storm with a peak intensity close to $45 \mathrm{kt}$, it now attains Category 1 strength with peak winds exceeding $60 \mathrm{kt}$. Thus, without the SST cooling of prior MJO, Olga's maximum winds would have been nearly $15 \mathrm{kt}$ higher and minimum sea-level pressure lower by about $13 \mathrm{hPa}$ (Fig. 3c). Differences in along-track SST (Fig. 3d) reveal that the pre-storm SSTs for Olga were reduced by nearly $1{ }^{\circ} \mathrm{C}$ by the MJO between 15 and 17 March. Without this cooling, the enthalpy flux out of the ocean would have been considerably higher. Averaged over the course of 2 days, the enthalpy flux increases by $67 \%$ in the "NO-WAKE" case with respect to its value of about $230 \mathrm{~W} \mathrm{~m}^{-2}$ in the "WAKE" case, allowing Olga to strengthen into a Category 1 hurricane in the "NO-WAKE" case.

\section{DISCUSSION}

Past research has documented the negative effects of lingering cold wakes of TCs on subsequent TCs that encounter them ${ }^{46}$.
Similarly, it was found that strong MJO events weaken subsequent events that immediately follow them through their SST footprints $^{28}$. The results from this study, where we demonstrate the cross-phenomena interaction between MJOs and TCs through the ocean, represent a shift in the prevailing understanding that MJOs can primarily influence TCs through a modulation of the largescale atmospheric circulation. Also, they point towards an improvement in prediction skill through realistic representation of air-sea coupled processes in models.

Furthermore, the oceanic influence of the MJO on Australian TCs presented here can also have longer-term consequences. For instance, stronger MJOs tend to induce more sea surface cooling as they pass over the MC region (Supplementary Fig. 2a). Also, the strength of MJOs while over the MC region appears to be on the decline (Supplementary Fig. 2b) as a result of gradual eastward expansion of the background climatological warm pool ${ }^{47}$. Thus, changes in MJO characteristics over time can induce corresponding changes in the MJO's influence on TCs over this region. Finally, the MJO-induced SST cooling over the MC is tightly related to the upper-ocean stratification over that region (Supplementary Fig. 3). With the latter projected to change under global warming ${ }^{48}$, the "braking" effect of MJOs on TC intensification over the MC region could be altered in future.

\section{METHODS \\ Data}

We obtain daily NOAA OI SST ${ }^{49}$ from https://psl.noaa.gov/data/gridded/ data.noaa.oisst.v2.highres.html for the period 1983-2019 to estimate MJOinduced SST change. We also obtain TRMM Microwave Imager daily SST for the period 1998-2014 from http://www.remss.com/missions/tmi/ to verify the signal based on NOAA OI SST. Five-day mean vertical ocean temperature and salinity profiles, and surface ocean fluxes from SODA3 (version 3.3.1) (37 $^{37}$ ocean reanalysis, obtained from https://www.soda.umd. edu for the period 1980-2015, are used to understand the role of various 
upper-ocean processes in MJO-induced SST change. To identify MJOs, we use time series of daily $\mathrm{RMM}^{36}$ index values, obtained for the period 1980-2018 from the Australian Bureau of Meteorology (http://www.bom. gov.au/climate/mjo/graphics/rmm.74toRealtime.txt).

TC track data for the period 1985-2018 are obtained from https:// emanuel.mit.edu/products and used to estimate the values of various atmospheric and oceanic parameters along TC tracks. WHOI OAFlux ${ }^{50}$ daily latent and sensible heat fluxes, obtained from http://oaflux.whoi.edu are used to estimate the enthalpy flux transfer at the air-sea interface under TCs. Daily NCEP-DOE 2 atmospheric reanalysis data ${ }^{51}$, obtained from (https://psl.noaa.gov/data/gridded/data.ncep.reanalysis2.html), and daily NOAA outgoing longwave radiation (OLR) ${ }^{52}$ obtained from https://www. psl.noaa.gov/data/gridded/data.interp_OLR.html, are used to estimate various TC-relevant atmospheric parameters and outgoing longwave radiation anomalies along TC tracks.

\section{Calculations}

MJO events are identified using the following procedure. First, a date is identified in the RMM index time series on which the phase 3 amplitude is larger than 1 . The next 30 days are then examined to see if phases 4,5 , and 6 occur at least once irrespective of the amplitude. If these two conditions are met, the MJO event is said to have propagated over the $M C$ region and selected for our analysis ${ }^{35}$.

The following parameters are estimated along TC tracks to understand the pre-storm large-scale environment: vertical shear of zonal wind evaluated between 200 and $850 \mathrm{hPa}$, relative humidity at $700 \mathrm{hPa}$, relative vorticity at $850 \mathrm{hPa}$, vertical velocity at $300 \mathrm{hPa}$, sea-level pressure, outgoing longwave radiation, and $\mathrm{SST}^{6}$. Specifically, we follow each MJO event and look for TC track locations that fall within a period. For each identified track location, we compute various pre-storm atmospheric parameters, pre-storm SST, the enthalpy flux under the storm and the intensification rate. Next, we follow a similar procedure to compute the same environmental and storm parameters for those TC track locations that fall outside that period. Finally, we examine the composite mean differences between the two sets of data and test for statistical significance in various parameters.

While the atmospheric parameters are averaged over a $5^{\circ} \times 5^{\circ}$ box centered over the storm, pre-storm SST and enthalpy fluxes are averaged over a $2^{\circ} \times 2^{\circ}$ box centered over the storm. The atmospheric parameters and pre-storm SST are estimated 2 days before the arrival of the storm. The enthalpy flux, on the other hand, is estimated on the day of the storm. The TC intensification rate at a location is estimated as the slope of the linear regression of the maximum wind speed over five successive 6-hourly track locations beginning with the current location. The dry stability of the atmosphere is estimated as $-\frac{\partial \theta}{\partial p}$ where $\theta$ is the potential temperature and $p$ is the pressure. Throughout the study for various analysis, the seasonal cycle is removed from different parameters. We use the Monte Carlo method of repeated random sampling to generate error bars for the PDFs. From a given distribution, we randomly select half of the samples to generate a PDF and repeat this process a hundred times. Following this, the mean and standard deviation computed across the PDFs yield the mean PDF and error bars, respectively.

\section{Numerical experiments}

To illustrate the MJO's oceanic influence on TCs, we performed numerical simulations of tropical storm "Olga" (15-19 March 2000), which occurred 5 days after the end of a MJO's phase 5, using the non-hydrostatic WRFARW version $4.0^{53}$. The model domain covers the region between $95 \mathrm{E}^{\circ}-125^{\circ} \mathrm{E}$ and $30^{\circ} \mathrm{S}$-Equator, with $4 \mathrm{~km}$ horizontal resolution and 35 terrain following vertical levels up to $50 \mathrm{hPa}$. The initial and boundary conditions, including SST, are from ERA5 reanalysis ${ }^{54}$ (https://www.ecmwf. int/en/forecasts/datasets/reanalysis-datasets/era5) with $31 \mathrm{~km}$ horizontal resolution, available from https://www2.mmm.ucar.edu/wrf/users/ download/free_data.html. Boundary conditions are updated every $6 \mathrm{~h}$. The physical parameterizations used are detailed in Supplementary Table 3. Eight ensemble members are created using combinations of four cloud microphysical schemes and two planetary boundary layer schemes. The integration of the model is carried out from 00 UTC 15 March 2000 to 12 UTC 19 March 2000. Using aforementioned model design, two sets of eight-member ensemble experiments are performed.

In the first set of experiments (WAKE), which represents the control case, TC Olga is forced with observed SST. In the second set of experiments (NOWAKE), TC Olga is forced with a SST from which the cooling induced by the prior MJO is removed. More specifically, the magnitude of negative SST anomaly on 00 UTC 15 March 2000, calculated with respect to the 10-day mean SST prior to phase 4 of the MJO, is added to the initial SST as perturbation in the NO-WAKE experiment. The initial perturbation is reduced every $6 \mathrm{~h}$ using the composite mean evolution of SST cooling averaged over the region $110^{\circ} \mathrm{E}-130^{\circ} \mathrm{E}$ and $15^{\circ} \mathrm{S}-5^{\circ} \mathrm{S}$ (Fig. 1C).

\section{DATA AVAILABILITY}

Model output are available on request from K.B. All other datasets used in this study are freely available for download from the various links provided in "Methods".

\section{CODE AVAILABILITY}

The WRF-ARW model code is freely available for download from the link provided in "Methods".

Received: 24 May 2021; Accepted: 29 September 2021; Published online: 27 October 2021

\section{REFERENCES}

1. Madden, R. A. \& Julian, P. R. Description of global-scale circulation cells in the tropics with a 40-50 day period. J. Atmos. Sci. 29, 1109-1123 (1972).

2. Wheeler, M. \& Kiladis, G. N. Convectively coupled equatorial waves: analysis of clouds and temperature in the wavenumber-frequency domain. J. Atmos. Sci. 56, 374-399 (1999).

3. Zhang, C. Madden-Julian Oscillation: bridging weather and climate. Bull. Am. Meteorol. Soc. 94, 1849-1870 (2013).

4. Kiladis, G. N., Straub, K. H. \& Haertel, P. T. Zonal and vertical structure of the Madden-Julian Oscillation. J. Atmos. Sci. 62, 2790-2809 (2005).

5. Camargo, S. J., Wheeler, M. C. \& Sobel, A. H. Diagnosis of the MJO modulation of tropical cyclogenesis using an empirical index. J. Atmos. Sci. 66, 3061-3074 (2009).

6. Klotzbach, P. J. The Madden-Julian Oscillation's impacts on worldwide tropical cyclone activity. J. Clim. 27, 2317-2330 (2014).

7. Gray, W. M. Hurricanes: their formation, structure and likely role in the tropical circulation. In Meteorology Over the Tropical Oceans (ed. Shaw, D.B.) 155-218 (Royal Meteorological Society, 1979).

8. Liebmann, B., Hendon, H. H. \& Glick, J. D. The relationship between tropical cyclones of the Western Pacific and Indian Oceans and the Madden-Julian Oscillation. J. Meteorol. Soc. Jpn. 72, 401-412 (1994).

9. Maloney, E. D. \& Hartmann, D. L. Modulation of hurricane activity in the Gulf of Mexico by the Madden-Julian Oscillation. Science 287, 2002-2004 (2000).

10. Hall, J. D., Matthews, A. J. \& Karoly, D. J. The modulation of tropical cyclone activity in the Australian region by the Madden-Julian Oscillation. Mon. Weather Rev. 129, 2970-2982 (2001).

11. Bessafi, M. \& Wheeler, M. C. Modulation of South Indian Ocean tropical cyclones by the Madden-Julian Oscillation and convectively coupled equatorial waves. Mon. Weather Rev. 134, 638-656 (2006).

12. Ho, C.-H., Kim, J.-H., Jeong, J.-H., Kim, H.-S. \& Chen, D. Variation of tropical cyclone activity in the South Indian Ocean: El Niño-Southern Oscillation and Madden-Julian Oscillation effects. J. Geophys. Res. 111, D22 (2006). https://doi.org/10.1029/ 2006JD007289.

13. Aiyyer, A. \& Molinari, J. MJO and tropical cyclogenesis in the Gulf of Mexico and Eastern Pacific: case study and idealized numerical modeling. J. Atmos. Sci. 65, 2691-2704 (2008).

14. Barrett, B. S. \& Leslie, L. M. Links between tropical cyclone activity and MaddenJulian Oscillation phase in the North Atlantic and Northeast Pacific Basins. Mon. Weather Rev. 137, 727-744 (2009).

15. Chand, S. S. \& Walsh, K. J. The influence of the Madden-Julian Oscillation on tropical cyclone activity in the Fiji region. J. Clim. 23, 868-886 (2010).

16. Kikuchi, K. \& Wang, B. Formation of tropical cyclones in the Northern Indian Ocean associated with two types of tropical intraseasonal oscillation modes. J. Meteorol. Soc. Jpn. 88, 475-496 (2010).

17. Ventrice, M. J., Thorncroft, C. D. \& Roundy, P. E. The Madden-Julian Oscillation's influence on African Easterly Waves and downstream tropical cyclogenesis. Mon. Weather Rev. 139, 2704-2722 (2011).

18. Klotzbach, P. J. El Niño-Southern Oscillation, the Madden-Julian Oscillation and Atlantic basin tropical cyclone rapid intensification. J. Geophys. Res. 117, D14 (2012). https://doi.org/10.1029/2012JD017714.

19. Krishnamohan, K., Mohanakumar, K. \& Joseph, P. The influence of Madden-Julian Oscillation in the genesis of north Indian Ocean tropical cyclones. Theor. Appl. Climatol. 109, 271-282 (2012). 
20. Yoneyama, K., Zhang, C. \& Long, C. N. Tracking pulses of the Madden-Julian Oscillation. Bull. Am. Meteorol. Soc. 94, 1871-1891 (2013).

21. Waliser, D. E., Murtugudde, R. \& Lucas, L. E. Indo-Pacific Ocean response to atmospheric intraseasonal variability: 1. Austral summer and the Madden-Julian Oscillation. J. Geophys. Res. 108, 3160 (2003).

22. Zhang, C. Madden-Julian Oscillation. Rev. Geophys. 43, RG2003 (2005).

23. Woolnough, S., Vitart, F. \& Balmaseda, M. The role of the ocean in the Madden-Julian Oscillation: implications for MJO prediction. Q. J. R. Meteorol. Soc. 133, 117-128 (2007).

24. Drushka, K., Sprintall, J. \& Gille, S. T. Subseasonal variations in salinity and barrierlayer thickness in the eastern equatorial Indian Ocean. J. Geophys. Res. 119, 805-823 (2014).

25. DeMott, C. A., Klingaman, N. P. \& Woolnough, S. J. Atmosphere-ocean coupled processes in the Madden-Julian Oscillation. Rev. Geophys. 53, 1099-1154 (2015).

26. Jensen, T. G., Shinoda, T., Chen, S. \& Flatau, M. Ocean response to CINDY/DYNAMO MJOs in air-sea-coupled COAMPS. J. Meteorol. Soc. Jpn. 93, 157-178 (2015).

27. De Szoeke, S. P., Edson, J. B., Marion, J. R., Fairall, C. W. \& Bariteau, L. The MJO and air-sea interaction in TOGA COARE and DYNAMO. J. Clim. 28, 597-622 (2015).

28. Moum, J. N., Pujiana, K., Lien, R.-C. \& Smyth, W. D. Ocean feedback to pulses of the Madden-Julian Oscillation in the equatorial Indian Ocean. Nat. Commun. 7, 1-7 (2016).

29. Rydbeck, A. et al. Ocean heat content and the intraseasonal oscillation. Geophys. Res. Lett. 46, 14558-14566 (2019).

30. Emanuel, K. A. An air-sea interaction theory for tropical cyclones. Part I. Steadystate maintenance. J. Atmos. Sci. 43, 585-605 (1986).

31. Holland, G. J. The maximum potential intensity of tropical cyclones. J. Atmos. Sci. 54, 2519-2541 (1997).

32. Emanuel, K. A. Thermodynamic control of hurricane intensity. Nature 401, 665-669 (1999).

33. Knutson, T. R. et al. Tropical cyclones and climate change. Nat. Geosci. 3, 157-163 (2010).

34. Lafleur, D. M., Barrett, B. S. \& Henderson, G. R. Some climatological aspects of the Madden-Julian Oscillation (MJO). J. Clim. 28, 6039-6053 (2015).

35. Burleyson, C. D., Hagos, S. M., Feng, Z., Kerns, B. W. \& Kim, D. Large-scale environmental characteristics of MJOs that strengthen and weaken over the Maritime Continent. J. Clim. 31, 5731-5748 (2018).

36. Wheeler, M. C. \& Hendon, H. H. An all-season real-time multivariate MJO index: development of an index for monitoring and prediction. Mon. Weather Rev. 132, 1917-1932 (2004).

37. Carton, J. A., Chepurin, G. A. \& Chen, L. SODA3: a new ocean climate reanalysis. J. Clim. 31, 6967-6983 (2018).

38. Drushka, K., Sprintall, J., Gille, S. T. \& Wijffels, S. In situ observations of Madden-Julian Oscillation mixed layer dynamics in the Indian and Western Pacific Oceans. J. Clim. 25, 2306-2328 (2012).

39. Halkides, D., Waliser, D. E., Lee, T., Menemenlis, D. \& Guan, B. Quantifying the processes controlling intraseasonal mixed-layer temperature variability in the tropical Indian Ocean. J. Geophys. Res. 120, 692-715 (2015).

40. Pei, S., Shinoda, T., Steffen, J. \& Seo, H. Substantial sea surface temperature cooling in the Banda Sea associated with the Madden-Julian Oscillation in the boreal winter of 2015. J. Geophys. Res. 126, e2021JC017226 (2021).

41. Dare, R. A. \& Davidson, N. E. Characteristics of tropical cyclones in the Australian region. Mon. Weather Rev. 132, 3049-3065 (2004).

42. Bureau of Meteorology, Australian Government. Climatology of Tropical Cyclones in Western Australia. (Bureau of Meteorology, accessed 4 April 2021); http://www. bom.gov.au/cyclone/climatology/wa.shtml.

43. Longley, I. et al. The North West Shelf of Australia - a Woodside perspective. In The Sedimentary Basins of Western Australia 3: Proc. Petroleum Exploration Society of Australia Symposium Vol. 27 (eds. Keep, M. \& Moss, S.) 88 (Petroleum Exploration Society of Australia, 2002).

44. Zhang, C. \& Dong, M. Seasonality in the Madden-Julian Oscillation. J. Clim. 17, 3169-3180 (2004).

45. Ramsay, H. A. \& Sobel, A. H. Effects of relative and absolute sea surface temperature on tropical cyclone potential intensity using a single-column model. J. Clim. 24, 183-193 (2011).

46. Balaguru, K., Taraphdar, S., Leung, L. R., Foltz, G. R. \& Knaff, J. A. Cyclone-cyclone interactions through the ocean pathway. Geophys. Res. Lett. 41, 6855-6862 (2014).

47. Roxy, M. et al. Twofold expansion of the Indo-Pacific warm pool warps the MJO life cycle. Nature 575, 647-651 (2019).
48. Kwiatkowski, L. et al. Twenty-first century ocean warming, acidification, deoxygenation, and upper-ocean nutrient and primary production decline from CMIP6 model projections. Biogeosciences 17, 3439-3470 (2020).

49. Reynolds, R. W. et al. Daily high-resolution-blended analyses for sea surface temperature. J. Clim. 20, 5473-5496 (2007).

50. Yu, L. \& Weller, R. A. Objectively analyzed air-sea heat fluxes for the global ice-free oceans (1981-2005). Bull. Am. Meteorol. Soc. 88, 527-540 (2007).

51. Kanamitsu, M. et al. NCEP-DOE AMIP-II reanalysis (R-2). Bull. Am. Meteorol. Soc. 83, 1631-1644 (2002).

52. Liebmann, B. \& Smith, C. A. Description of a complete (interpolated) outgoing longwave radiation dataset. Bull. Am. Meteorol. Soc. 77, 1275-1277 (1996).

53. Skamarock, W. C. et al. A Description of the Advanced Research WRF Model Version 4, 145 (National Center for Atmospheric Research, 2019).

54. Hersbach, H. et al. The ERA5 global reanalysis. Q. J. R. Meteorol. Soc. 146, 1999-2049 (2020).

\section{ACKNOWLEDGEMENTS}

K.B., L.R.L., S.M.H. and S.K. are supported by the Office of Science (BER) of the U.S. Department of Energy as part of the Regional \& Global Model Analysis (RGMA) program area. The Pacific Northwest National Laboratory is operated for DOE by Battelle Memorial Institute under contract DE-AC05-76RL01830. The computations were mainly carried out using the computing resources at the National Energy Research Scientific Computing Center (NERSC), a U.S. Department of Energy Office of Science User Facility located at Lawrence Berkeley National Laboratory, operated under Contract No. DE-AC02-05CH11231.

\section{AUTHOR CONTRIBUTIONS}

K.B., L.R.L. and S.M.H. developed the main idea. K.B. performed the analysis of observations. K.B., L.R.L. and S.M.H. wrote the paper. S.K. conducted model simulations and analyzed the output.

\section{COMPETING INTERESTS}

The authors declare no competing interests.

\section{ADDITIONAL INFORMATION}

Supplementary information The online version contains supplementary material available at https://doi.org/10.1038/s41612-021-00208-4.

Correspondence and requests for materials should be addressed to Karthik Balaguru.

Reprints and permission information is available at http://www.nature.com/ reprints

Publisher's note Springer Nature remains neutral with regard to jurisdictional claims in published maps and institutional affiliations.

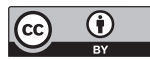

Open Access This article is licensed under a Creative Commons Attribution 4.0 International License, which permits use, sharing, adaptation, distribution and reproduction in any medium or format, as long as you give appropriate credit to the original author(s) and the source, provide a link to the Creative Commons license, and indicate if changes were made. The images or other third party material in this article are included in the article's Creative Commons license, unless indicated otherwise in a credit line to the material. If material is not included in the article's Creative Commons license and your intended use is not permitted by statutory regulation or exceeds the permitted use, you will need to obtain permission directly from the copyright holder. To view a copy of this license, visit http://creativecommons. org/licenses/by/4.0/.

(c) The Author(s) 2021, corrected publication 2021 